\title{
Ecologia e resistência no rastro do voo da bruxa: a cosmopolítica como exercício de filosofia especulativa
}

\author{
ALYNE DE CASTRO COSTA *
}

* Doutoranda em Filosofia pela PUC-Rio

Bolsista Faperj Nota 10 alyneccosta@gmail.com
RESUMO Muitos dos pensadores que vêm se debruçado sobre a questão da catástrofe ecológica que marca nosso tempo alertam para a necessidade de "alargar nosso círculo político" (LATOUR, 2004) com vistas a melhor acomodar os agentes outros-que-humanos que tal catástrofe põe em evidência. Mas como esse alargamento poderia se dar? Ou, dito de outro modo: quais os possíveis modos de participação desses seres na política? Seria sob o modo da representação - e, nesse caso, alguém (algum humano) iria representá-los ou eles se representariam de algum modo por si mesmos? Se tais seres não possuem linguagem para expressar seus desejos e preferências, a política não continuaria sendo uma seara exclusivamente humana?

Para tentar esboçar uma resposta a essas perguntas - que, evidentemente, remetem a uma determinada concepção de "política" -, pretendo recorrer ao conceito de "cosmopolítica”, cunhado por Isabelle Stengers, como um caminho para pensar que tipo de círculo político seremos capazes de constituir se pudermos pensar a política para além dos elementos habitualmente a ela associados, como a representação, a linguagem e o consenso, e que tipos de divergências e antagonismos esses elementos mascaram. Pretendo neste trabalho, assim, apresentar a "cosmopolítica” como um exercício daquilo que Stengers, seguindo Alfred Whitehead, chama de "filosofia especulativa" e apontar em que medida ela indica uma abertura para novas maneiras de pensar e agir - ou, por que não?, de resistir - diante dos perigos que se acumulam em nossa história (tanto a humana quanto a biológica e a geológica).

PALAVRAS-CHAVE Crise ecológica, cosmopolítica, filosofia especulativa, Stengers. 
ABSTRACT For many scholars who have been addressing in their works the ecological catastrophe of our time an "enlargement of our political circle" (LATOUR, B.; 2004) is needed in order to make room for the other-than-human agents that this catastrophe put in evidence. But how could this enlargement take place? Or in other words: what are the possible ways for these beings to take part in politics? Would it be under a representative regime - and, in such a case, anyone (any human) would represent them or would they somehow represent themselves? If these beings are dispossessed of language to express their wishes and preferences, would politics remain a field exclusively human?

In an effort to outline an answer to these questions - which, evidently, refer to a certain notion of "politics" -, I intend to make use of the concept "cosmopolitics", of Isabelle Stengers, as a way to think what kind of political circle we would be able to create if we could think politics beyond the elements currently associated to it (like representation, language and consensus) and what kinds of divergences and antagonisms these elements usually hide. In this text, therefore, I present cosmopolitics as an exercise of what Stengers, following Alfred Whitehead, calls "speculative philosophy", and discuss in what extent the concept points to an opening of new ways of thinking and acting - or, why not?, resisting - faced to the dangers that accumulate in our history (be it the human, the biological or the geological one).

KEYWORDS Ecological crisis, cosmopolitics, speculative philosophy, Stengers.

Nos últimos anos, temos visto uma profusão de produções teóricas a respeito da catástrofe ecológica que marca nossa época - e "marca", aqui, tem um sentido literal, considerando que, no próximo semestre, geólogos do mundo todo se reunirão para avaliar se os vestígios da atividade humana recente encontrados nos estratos geológicos e as graves interferências antrópicas nos ciclos biológicos, químicos e físicos da Terra são evidências suficientes para atestar que efetivamente nós, "humanos", ganhamos uma época para chamar de "nossa", o Antropoceno. ${ }^{1}$ Entre as diversas abordagens sobre o tema, as que menos interessam particularmente são as que não só percebem nesta catástrofe a insuficiência da bipartição "natureza-cultura",

1 Como explica Ian Angus, o termo "Antropoceno" significa a época em que "estratos geológicos são dominados por remanescentes de origem humana recente" (ANGUS, I.; 2015). Dizer que o Antropoceno é a "nossa" época, espero que fique claro no decorrer do texto, é uma ironia: não só não podemos precisar o que é o anthropos que a nomeia, como também há que se desconfiar das narrativas que fazem do Antropoceno a época em que finalmente os "homens" assumem o controle da "natureza". 
instituída ao longo da modernidade, para dar conta da dinâmica das relações entre os existentes orgânicos e inorgânicos que constituem o mundo em que vivemos, mas também reconhecem no suposto universalismo de tal bipartição a expressão de um colonialismo que expropriou outros povos e outros seres, de seus modos próprios de existir, de produzir e de se relacionar. Tratam-se, portanto, de interpretações duplamente materialistas da história das relações na Terra: além de afirmarem que aquilo que costumávamos pensar como "natureza” é o produto histórico das interações entre os diversos existentes - compreendendo a história, ou mesmo a política, segundo uma concepção que extrapola o domínio das relações humanas -, demonstram que o suposto universalismo do par "natureza-cultura” serve a um exercício de poder que submete não só determinadas populações humanas, as quais acabam por ser destruídas ou, no máximo, educadas e toleradas - a tolerância como "a face humana do capital multinacional", sugere Steven Shaviro (2005) -, como também incontáveis seres não-humanos. Poderíamos pensar tais abordagens como constituindo um materialismo geohistórico,? ${ }^{2}$

Segundo essas interpretações, portanto, faz-se necessário “alargar nosso círculo político", como diz Bruno Latour (2013), de forma a acomodar esses agentes outros-que-humanos que a catástrofe ecológica põe mais que nunca em evidência; ou, para falar como Marisol de la Cadena, é preciso trazer de volta à cena política os antagonismos, “a discordância entre mundos”, a perspectiva dos "mundos múltiplos cruciais para a possibilidade do político" como forma de resistir à empreitada modernista capitalista que se empenhou em fazer da política um único mundo habitado por muitas culturas

2 N'A Ideologia Alemã, há uma passagem em que, se pudermos efetuar algumas substituições para retirar a centralidade do papel atribuído ao "homem" nos processos históricos, encontramos uma interessante análise materialista sob a perspectiva geohistórica (expressão utilizada por Bruno Latour nas Conferências Gifford [2013]) e uma boa definição do que poderia ser um comunismo estendido aos seres não-humanos - um cosmonismo, talvez? "O cosmonismo distingue-se de todos os movimentos anteriores porque revoluciona os fundamentos de todas as relações de produção e de intercâmbio precedentes e porque pela primeira vez aborda conscientemente todos os pressupostos naturais como criação dos seres que existiram anteriormente, despojando-os de seu caráter natural e submetendo-os ao poder dos agentes associados. Sua organização é, por isso, essencialmente ecológica, a produção material das condições dessa associação; ele faz das condições existentes as condições da associação. O existente que o cosmonismo cria é precisamente a base real para tornar impossível tudo o que existe independentemente de todos os seres, na medida em que o existente nada mais é do que um produto do intercâmbio anterior dos próprios seres" (ENGELS, F.; MARX, K.; 2007, p. 67), destaque para minhas alterações). Agradeço ao amigo Maikel da Silveira pela sugestão da expressão materialismo geohistórico para nomear tal releitura. 
e uma única natureza (De la CADENA, M.; 2010, p. 345-346). Mas de que maneira esses múltiplos mundos e seus agentes outros-que-humanos podem integrar a política? Como seus interesses poderiam ser expressos e considerados, e que tipo de política isso significaria?

Talvez a imagem mais imediata que podemos fazer da sua inclusão na política seja próxima daquela retratada por Miguel Gomes no capítulo intitulado "Lágrimas da juíza” de sua trilogia As mil e uma noites (2015). Nele, a juíza em questão tenta julgar um crime relativamente simples, mas, antes que possa chegar a um veredicto, novos personagens não param de se apresentar e trazer informações sobre outros crimes relacionados aos anteriores, arrolando novos réus e vítimas ao julgamento; entre estes, estão um gênio que obriga um senhor a fazer coisas estúpidas,e uma vaca que, após ter sido roubada, sofre um acidente e conhece uma oliveira, a qual por sua vez lhe conta o quanto também sofreu na mão dos mesmos ladrões. A bem da verdade, este capítulo não deixa de evocar a imagem histórica de um passado não tão distante assim, quando julgamentos de animais eram previstos em diversos sistemas jurídicos europeus, incluindo o Direito Romano. ${ }^{3}$

Uma outra imagem da participação dos não-humanos na política é fornecida pelo conceito de "Parlamento das Coisas”, apresentado por Bruno Latour no seu já célebre livro Jamais fomos modernos (1994). Segundo o autor, tal parlamento poderia se instaurar se os povos ditos ocidentais pudessem reconhecer que todo corpo político é formado por agentes humanos e outros-que-humanos que se mobilizam mutuamente na composição de um coletivo. Segundo o autor, neste parlamento

[...] as naturezas estarão presentes, mas com seus representantes, os cientistas, que falam em seu nome. As sociedades estarão presentes, mas com os objetos

3 Como lembra Silvia Federici no livro Caliban e a bruxa, "durante a Idade Média e até o século XVI, [os animais] eram considerados seres inteligentes, responsáveis, com uma imaginação particularmente desenvolvida e inclusive com capacidade de falar. [...E $] \mathrm{m}$ alguns países da Europa, se julgavam os animais, e às vezes [eles] eram executados publicamente por crimes que haviam cometido. Um advogado lhes era designado e o processo - julgamento, condenação e execução - era realizado com todas as formalidades legais. Em 1565, os cidadãos de Arles, por exemplo, pediram a expulsão das lagostas de seu povo e, em outro caso, excomungaram-se vermes (gusanos) que infestavam uma paróquia. O último julgamento de um animal teve lugar na França em 1845. Os animais também eram aceitos como testemunhas para o compurgatio. Um homem que havia sido condenado por assassinato compareceu ante à corte com seu gato e seu galo, e em sua presença jurou ser inocente e foi liberado (FEDERICI, S.; 2004, p. 205, tradução minha). 
que as sustentam desde sempre. Pouco nos importa que um dos mandatários fale do buraco [da camada] de ozônio, que um outro represente as indústrias químicas, um terceiro represente os operários destas mesmas indústrias químicas, um quarto os eleitores, um quinto a meteorologia das regiões polares, que um outro fale em nome do Estado; pouco nos importa, contanto que eles se pronunciem todos sobre a mesma coisa, sobre este quase-objeto que criaram juntos, este objeto-discurso-natureza-sociedade [...]. Os imbróglios e as redes que não possuíam um lugar possuem agora todo o espaço. São eles que é preciso representar, é em torno deles que se reúne, de agora em diante, o Parlamento das Coisas (LATOUR, B.; 1994, p. 142). ${ }^{4}$

No entanto, a noção de "política" que pretendo abordar neste trabalho é aquela na qual a participação dos agentes políticos não esteja necessariamente condicionada pelos imperativos da linguagem, da representação, da expressão, do "lugar de fala", para usar uma noção muito em voga nos debates políticos atuais. Nela, o foco da cena política não é a deliberação, mas a hesitação; tampouco se trataria de um processo de submissão das particularidades em torno de um entendimento comum, mas sim de uma compreensão da política como um exercício de fazer proliferar as divergências, os modos próprios de existir e produzir dos diversos coletivos que povoam a Terra. Para isso, apresentarei alguns aspectos do conceito de cosmopolítica de Isabelle Stengers, no intuito de apontar em que medida ele constitui um exercício de filosofia especulativa capaz de “descentrar a política do humano" e de suspender os maus hábitos que nos fazem transformar nossas formas próprias de produção de sentido e de relações em mecanismos de desqualificação de outras práticas. Em seguida, pretendo explorar que tipos de resistência podem se constituir em decorrência desta experiência especulativa.

Stengers explica que o prefixo “cosmos” do conceito de cosmopolítica não diz respeito à intenção de instaurar ideais supostamente universais para orientar a política, de forma a permitir a convivência, finalmente perpétua e pacífica, daqueles que ela congrega - como poderíamos erroneamente pensar induzidos pela noção kantiana de

4 Em maio de 2015, seis meses antes da 21a Conferência Internacional sobre o Clima (COP-21) que teve lugar em Paris no fim do mesmo ano, Latour foi um dos idealizadores de uma espécie de encenação do Parlamento das Coisas: o COP 21 Make It Work reuniu 210 estudantes de diversas nacionalidades para realizar uma simulação experimental das negociações climáticas, na qual as delegações não se restringiam a representar países, mas também “entidades” tão variadas quanto a Amazônia, a internet, o Saara, a juventude, os principais setores da economia, as regiões polares e os ativos de petróleo improdutivos (stranded oil assets), entre outras (cf. www.cop21makeitwork.com e http:// fr.calameo.com/read/00416045477d 4 fgfc21a8). 
cosmopolitismo. Ele evoca, ao contrário, a necessidade de desacelerar a urgência pela decisão e fazer gaguejar as certezas de que sabemos tudo o que achamos que sabemos a respeito de "nós"5 mesmos e das práticas que nos definem. Isto porque, quando se trata de negociar problemas que parecem globais, é sempre o “"nosso” conhecimento, os fatos produzidos por 'nosso' equipamento técnico, mas também os julgamentos associados com 'nossas' práticas que estão predominantemente no controle” (STENGERS, I.; 2004, p. 2). O “cosmos” da cosmopolítica, assim, é um operador de equali-

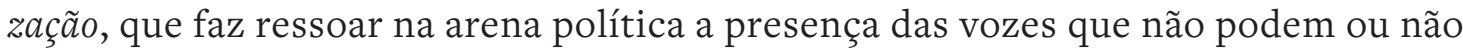
querem responder às exigências modernas/ocidentais para sua participação; ele é a introdução de uma experiência de desterritorialização (vale uma nota explicando o conceito) | que abala a confiança na validade universal dessas práticas modernas, na medida em que nos leva a hesitar ao sentir, por meio de um "temor" que nos atravessa (passing fright), a presença de “outros” que seriam provavelmente desqualificados como não tendo nada a propor.

Mas que vozes são essas que se fazem presentes em sua inexpressão? De acordo com a autora, o valor próprio de qualquer prática - seja ela científica, filosófica, religiosa, artística etc. - é a sua efetividade em introduzir novos seres (novas agências), ou, mais precisamente, de estabelecer novas relações no mundo no qual tais práticas fazem parte, em resposta a determinados problemas que cada prática se dispõe a solucionar. Na criação desta verdade imanente a cada prática - a “verdade do relativo", em lugar da relatividade da verdade (idem, 2005b, p. 158) -, os termos da relação não a precedem: eles emergem simultaneamente, num processo de “captura recíproca” que faz surgir

5 Stengers usa o pronome "nós" (e os possessivos correlatos "nosso[s]"/"nossa[s]") para salientar o coletivo a que ela afirma pertencer: o coletivo europeu, moderno, criador de determinados modos de produção de conhecimento comumente tratados como universais (ou civilizados, ou racionais...). Cabe lembrar que a autora é belga e, ao longo de sua carreira filosófica, trabalhou estreitamente com cientistas, tendo ela mesma se graduado em química; é por isso que ela se diz, em diversos textos, herdeira das práticas modernas (e daí as muitas referências, neste trabalho, à prática científica, sobre a qual a autora tanto escreveu). Ao mesmo tempo, as aspas servem para sinalizar que é preciso, justamente, reconhecer a legitimidade de outras práticas que não as modernas, desconfiando dessa autoproclamação de universalidade, como veremos ao longo do texto. Dito isto, e reconhecendo que as maneiras como os saberes ocidentais (impostos à custa de muita exploração) são praticados no hemisfério Sul não coincidem com as formas como o são nos países do Norte, aceito (ao menos provisoriamente, neste trabalho) me posicionar junto a Stengers e assumir também como "minhas" as práticas ocidentais - afinal, ao fazer filosofia, me dispus a produzir segundo as condições imanentes a esta prática, por mais que possamos (e devamos) questionar as implicações políticas que tal prática possa ensejar. 
ao mesmo tempo as identidades do "sujeito" criador e do “objeto" criado. Pensemos nas obrigações que devem ser atendidas pelo cientista intrigado com a possibilidade de que um "novo ente" esteja agindo em determinada situação, e nas exigências que devem ser cumpridas por esse "candidato" a objeto científico, para que, ao final do processo de criação, possam emergir as figuras de Pasteur e dos micróbios, para usar um exemplo conhecido da filosofia da ciência (LATOUR, B.; 2001); ${ }^{6}$ ou nas rigorosas obrigações e exigências mencionadas por Davi Kopenawa e Bruce Albert no livro A Queda do Céu (2015), necessárias à criação simultânea, por captura/constituição recíproca, do xamã e dos espíritos da floresta (xapiri), termos que só existem em relação.7 A verdade imanente a uma prática, portanto, é a coprodução simultânea da relação e de seus termos, e o "sucesso" de uma prática se deve à sua efetividade em engajar, ao mesmo tempo que produz, os interessados na questão que determinada prática mobiliza. Dessa forma, toda prática é política, e os agentes que dela participam não podem mais ser apenas os humanos: as vozes que a cosmopolítica faz repercutir dizem respeito ao reconhecimento da participação ativa de outros-que-humanos na criação imanente a cada prática, bem como à possibilidade do estabelecimento de "possíveis modos não-hierárquicos de convivência" (STENGERS, I.; 2011, p. 356) entre os seres divergentes que cada prática cria e por meio dos quais se afirma, na medida em que seu valor deixa de ser avaliado segundo os critérios de produção associados a uma única prática.

6 Poder-se-ia insistir em afirmar que a mobilização parte dos agentes humanos, já que não só são eles que tratam de atrair o interesse dos não-humanos, como também são quem deliberam, discutem e comunicam os resultados de sua criação; porém, se, do ponto de vista das práticas, “o humano" é o resultado de uma estabilização tardia de uma criação híbrida, da qual ele emerge enquanto "sujeito" ao mesmo tempo em que o outro termo da relação emerge como "objeto", conferir uma unidade ao humano e atribuir-lhe o privilégio de saber o que está fazendo ou dizendo é estabelecer uma "resposta estática [transcendente] à emergência bem-sucedida de um novo público [imanente]"; voltamos, assim, ao - ou não teremos saído do - reino dos universais. Ainda nesse contexto, Stengers lembra que, para se afirmar o que é o "próprio" do homem, possivelmente terá de se recorrer a elementos genéticos, linguísticos, psicológicos, físicos etc., isto é, o humano sendo determinado por entes que não ele mesmo.

7 É interessante mencionar alguns trechos de A Queda do Céu em que mostram as exigências a que Kopenawa e seu povo submetiam o Deus cristão, de cujo poder os missionários evangelizadores tentavam lhes convencer, para verificar sua existência enquanto divindade e a eficácia de sua performance: "Perguntávamos a eles [aos brancos]: 'Mas onde afinal vive esse que vocês chamam de Teosi?”; “Fechamos os olhos para falar com Teosi e não vemos nada. [...] É verdade, cada um de nós tentava, no fundo do peito, se dirigir a Teosi. Mas por mais que nossos ouvidos estivessem atentos, não ouvíamos nunca suas palavras" (ALBERT, B.; KOPENAWA, D.; 2015, p. 257; 260). Para Kopenawa, ao menos, o Deus cristão não passou no teste... 
Não sendo precisamente uma atividade, uma negociação ou uma prática, a cosmopolítica é um exercício de filosofia especulativa, por meio da qual se pretende "salvar" tudo o que integra nossa experiência dos hábitos de julgar e hierarquizar (ibidem, p. 402), abrindo espaço para que outros "esperanças e dúvidas, sonhos e medos" influenciem a forma como os problemas são colocados; não seria justamente essa abertura para além do consensualmente estabelecido a condição indispensável para a criação? Especificamente no que se refere à prática filosófica, cabe lembrar aqui a concepção deleuzo-guattariana de “conceito” endossada por Stengers: segundo os autores, pensar “implica uma espécie de experimentação tateante, e seu traçado recorre a meios pouco confessáveis, pouco racionais e razoáveis. [...] Pensar é sempre seguir a linha de fuga do voo da bruxa" (DELEUZE, G.; GUATTARI, F.; 1992, p. 58-59). A filosofia enquanto criação especulativa, portanto, diz respeito a tornar-se capaz de pensar na presença desses outros silenciados e desqualificados por práticas que arrogam para si uma efetividade universal. Dito de outro modo, a verdade própria à prática filosófica, "sua divergência ativa específica", reside na sua capacidade de contra-efetuar tais hábitos desqualificadores, de resistir à tentação de usar o produto de sua criação para estabelecer uma posição de poder, segundo a qual ela, a filosofia, se arrogaria o direito de discernir entre uma suposta verdade transcendental e as meras opiniões que devem ser combatidas.

Stengers afirma que, historicamente, a filosofia vem se posicionado como uma aliada da Ciência na desqualificação de outros modos de existência e produção, a qual se manifesta na cruzada empreendida contra a "opinião": de fato, foi a filosofia que forneceu as armas políticas de desqualificação que a Ciência emprega - lembremos que a filosofia, enquanto “coisa grega”, produto da polis, nasce da necessidade política de estabelecer as "instâncias que permitam julgar acerca do bem-fundado das pretensões” dos cidadãos rivais (DELEUZE, G.; GUATTARI, F.; op. cit., p. 18). No entanto, os universais erigidos pela Ciência e pela filosofia não são politicamente neutros: é por meio deles que o Estado capitalista converte o poder inventivo dessas práticas em uma máquina de destruição de outras formas de existência e criação. Desse modo, o apelo à universalidade é a "vulnerabilidade específica” destas práticas que o capitalismo explora para fazer rodar o sistema de equivalência geral que o caracteriza enquanto axiomática universal, aplainando as diferenças e formas particulares de produção social (idem, 2012). 
Decerto, as maiores vítimas dessa aliança contra a opinião da qual o projeto modernizador capitalista se valeu foram as “outras práticas”, muitas das quais chegaram a praticamente desaparecer - "a fumaça das bruxas queimadas ainda perdura sob nossas narinas" (STARHAWK apud STENGERS, I.; 2012). Porém, hoje mais do que nunca, são as próprias condições de produção das práticas modernas que se encontram ameaçadas pela investida capitalista, na medida em que cada vez mais os cientistas são demandados a "merecer o dinheiro que recebem" e produzir diretamente o que o capitalismo lhes exige - vide, por exemplo, o caso dos vultuosos investimentos em pesquisas de biotecnologia, vinculados a interesses industriais muito claros, como a produção de alimentos transgênicos. Para resistir à apropriação capitalista, Stengers propõe, filosofia e ciência precisam se desvencilhar do hábito de contrapor razão e opinião, reconhecendo que sobreviveram à fúria modernizadora não porque mereceram, mas por terem sido domesticadas para servir a interesses que não os seus próprios; quem sabe, dessa forma, elas não possam ser capazes de produzir outros tipos de alianças além daquelas que delas querem se apropriar (2005b).

Com a proposta cosmopolítica, a autora deseja abrir caminho para a composição de um poder inventivo capaz de resistir ao poder axiomático capitalista (STENGERS, I.; 2011, p. 413): de que política seremos capazes se deixarmos de nos ancorar em bases universalistas, antropocêntricas ou etnocêntricas? O que poderemos criar se os antagonismos retornarem à cena política, se deixarmos proliferar as divergências, se pudermos suspender a pressa da decisão? Que tipo de problemas seremos capazes de formular se, em vez de decidir por, pudermos decidir com e na presença daqueles que nossa crença em universais contribuiu para silenciar e destruir?

Para finalizar, gostaria de retomar o tema da crise ecológica que me conduziu por este caminho cosmopolítico. Stengers chama de "ecologia política” ou "ecologia das práticas” a proposição de pensar recusando ativamente qualquer recurso ou critério que transcenda determinada questão e o meio concreto em que ela emerge. "Pensar pelo meio”, já dizia Deleuze: “através do meio”, dispensando qualquer solo ou horizontes seguros, mas também “com o entorno”, sem se autorizar partir do particular produzido de forma imanente para um universal que poderia existir para além de suas condições de criação (2005b). É nesse sentido que Brian Massumi afirma que a ecologia política, enquanto prática cosmopolítica, é uma “tecnologia social da pertença, que assume a coexistência e o devir-com como o habitat das práticas” (MASSUMI, B; 
apud STENGERS, I.; 2005a, p. 183). Diante disso - e sabendo que o que vem a seguir pode soar um tanto abrupto, já que não disponho mais de tempo -, um possível caminho para abordar a catástrofe ecológica nos moldes da ecologia (cosmo)política consiste na capacidade tanto de reconhecer a agência de novos seres no registro das nossas práticas - por exemplo, levar a sério as evidências científicas da mudança climática e permitir que sua presença modifique nossa forma de agir e viver no mundo - quanto de tratar como legítimas as diferentes maneiras como a questão climática é colocada para diversos existentes. Como propõe Patrice Maniglier,

A Terra é nossa equivocação real; ela é o solo “comum” que só existe por meio das diferentes maneiras pelas quais sua unificação mesma é feita. A Terra não é uma identidade transcendente: é a dinâmica de versões divergentes de si mesma. A Terra, assim, só existe porque faz sentido dizer que a entidade revelada pelos relatórios do IPCC e a "grande terra-floresta" apresentada pelo xamã amazônico Davi Kopenawa são de fato contínuas uma à outra, o que significa que temos de compreender como uma se torna a outra, sem que uma seja apenas uma metáfora ou apenas uma representação da outra. (MANIGLIER, P.; 2015, tradução minha).

Talvez assim possamos constituir novas possibilidades de alianças, inventar outras formas de agir coletivamente, adquirindo a autonomia para buscar respostas fora das “alternativas infernais” capitalistas (STENGERS, I.; 2009) e a capacidade de prestar atenção (ibidem) que a convivência cosmopolítica exige.

\section{REFERÊNCIAS BIBLIOGRÁFICAS}

ANGUS, I. (2015). __ “Anthropocene: What's in a name?” In: Climate \& Capitalism [online]. 9 nov. 2015. Disponível em: <http://climateandcapitalism.com/2015/11/o9/ anthropocene-whatsinaname/?utm_source=feedburner\&utm_medium=feed $>$. Último acesso em: 16 mai. 2016.

De la CADENA, M. (2010). "Indigenous Cosmopolitics in the Andes: Conceptual Reflections beyond 'Politics”'. In: Cultural Anthropology, vol. 25, no. 2, pp. 334-370.

DELEUZE, G.; GUATTARI, F. (1992). O que é a filosofia? Trad. Bento Prado Jr. e Alberto Alonso Muñoz. Rio de Janeiro: Editora 34. 
(2012). Mil Platôs: Capitalismo e esquizofrenia 2. Vol 5. $2^{\mathrm{a}}$ edição. Trad. Peter Pál Pelbart e Janice Caiafa. São Paulo: Editora 34.

KOPENAWA, D.; ALBERT, B. (2015). A queda do céu: Palavras de um xamã yanomami. Trad. Beatriz Perrone-Moisés. 1a ed. São Paulo: Companhia das Letras.

LATOUR, B. (1994). Jamais Fomos Modernos: Ensaio de Antropologia Simétrica. Trad. Carlos Irineu da Costa. Rio de Janeiro: Editora 34.. - (2001). Pasteur: Guerre et paix des microbes, suivi de Irréductions. Paris: La Découverte.

- (2013). Facing Gaia: A new inquiry into Natural Religion. Palestras proferidas no âmbito das Gifford Lectures, na Universidade de Edimburgo. Edimburgo: 18 a 28 fev. 2013. Disponível em: $<$ http://www.ed.ac.uk/humanities-soc-sci/news-events/lectures/gifford-lectures/archive/series-2012-2013/bruno-latour>. Último acesso em: 16 mai. 2016. MANIGLIER, P. (2015). "How many Earths? What Climate Warming requires from metaphysics”. Comunicação apresentada na Casa do Povo. São Paulo: 29 out. 2015.

MARX, K.; ENGELS, F. (2007). A ideologia alemã. Trad. Rubens Enderle, Nélio Schneide e Luciano Cavini Martorano. São Paulo: Boitempo.

SHAVIRO, S. (2005). “Cosmopolitics” [resenha]. In: The Pinocchio Theory [online]. Disponível em: <http://www.shaviro.com/Blog/?p=401>. Último acesso em: 16 mai. 2016.

STENGERS, I. (2004). “The cosmopolitical proposal”. Disponível em: <http://mnissen. psy.ku.dk/Undervisning/Stengerso5.pdf>. Último acesso em: 16 mai. 2016.

(2005a). "Introductory notes on the ecology of practices". In: Cultural Studies Review. Vol. 1, N. 1, Mar. 2015, p. 183-196.

— (2005b). "Deleuze and Guattari’s last enigmatic message”. In: Angelaki: Journal of the Theoretical Humanities. Volume 10, Issue 2, p. 151-167.

. (2011). Cosmopolitics II. Translated by Robert Bononno. Minneapolis: University of Minnesotta Press.

(2012). “Reclaiming animism”. In: E-Flux [online]. N. 36, Jul. 2012. Disponível em: <http://www.e-flux.com/journal/reclaiming-animism/>. Último acesso: 16 mai. 2016. 